\title{
Inborn errors of metabolism in the United Arab Emirates: Are our future healthcare providers knowing enough about it-A cross- sectional study
}

\author{
Javedh Shareef ${ }^{*}$ (D), Sathvik Belagodu Sridhar ${ }^{1}$, Atiqulla Shariff¹, Mustafa Mohamed Sabah², Maadh Younus Hameed ${ }^{2}$ \\ ${ }^{1}$ Department of Clinical Pharmacy and Pharmacology, Ras Al Khaimah Medical and Health Science University, Ras Al Khaimah, United Arab Emirates. \\ ${ }^{2}$ RAK College of Pharmaceutical Sciences, Ras Al Khaimah Medical and Health Science University, Ras Al Khaimah, United Arab Emirates.
}

\begin{tabular}{l}
\hline ARTICLE INFO \\
\hline Received on: 04/04/2021 \\
Accepted on: 08/06/2021 \\
Available Online: 03/10/2021 \\
\\
\hline Key words: \\
Inborn error of metabolism, \\
knowledge, cross-sectional \\
study, students.
\end{tabular}

\begin{abstract}
Health literacy and positive attitude may influence the community in reducing the morbidity and mortality associated with the inborn errors of metabolism (IEM). This study aimed to assess the knowledge and attitude related to IEM among health science university students in the United Arab Emirates. A cross-sectional survey-based study was carried out over 6 months using a self-administered questionnaire. Four hundred and fourteen students completed the study. The overall mean scores were compared using the $t$-test. There was a statistically significant $(p<0.0001)$ difference between knowledge and attitude scores among the study respondents. Most of the study participants had inadequate knowledge and had a positive attitude towards the IEM, which was statistically significant $(p<0.0001)$. The study also identified paucity among the study participants in recognizing the symptoms and most common IEM. Lectures (30.74\%) followed by the Internet (19.25\%) and healthcare professionals $(18.72 \%)$ were the most cited sources of information. The study showed a low level of knowledge about IEM despite a positive attitude among respondents, emphasizing the need for such health-related subjects in the curriculum. This will enable the people to make informed decisions and instill into society the right attitude towards the consequent prevention and control of IEM.
\end{abstract}

\section{INTRODUCTION}

Inborn errors of metabolism (IEM) include a broad class of genetic diseases involving disorders transmitted as autosomal recessive, leading to a significant cause of morbidity and mortality in infants and children. The majority are due to unique gene defects that encode enzymes that facilitate various substances (substrates) into other products. In most disorders, problems occur due to the accumulation of toxic substances or interference with regular operation or the effects of reduced ability to synthesize essential compounds (Al Ali et al., 2006; Al-Jasmi et al., 2016).

The most common IEM identified in the United Arab Emirates are biotinidase deficiency, phenylketonuria,

\footnotetext{
*Corresponding Author

Javedh Shareef, Department of Clinical Pharmacy and Pharmacology, Ras Al Khaimah Medical and Health Science University, Ras Al Khaimah, United Arab Emirates.E-mail: javedh@ rakmhsu.ac.ae
}

3-methylcrotonyl glycinuria, and argininosuccinic aciduria. In these disorders, the body cannot break down several types of sugars, proteins, amino acids, and other nutrients. Most disorders are inherited and passed on through the faulty genes of both parents (Al-Jasmi et al., 2016; Al-Shamsi et al., 2014). The clinical features include convulsions, food avoidance, insufficient feeding in infants, irritability, vomiting, lethargy, lighter skin, hair color, and delayed developmental skills. Most of these conditions may be identified through neonatal screening. Delay in the diagnosis and treatment can lead to negative adverse outcomes, including neuropsychological dysfunction, mental retardation, and death (Zain, 2017).

A study carried out in the United Arab Emirates showed that 1,787 Emiratis are suffering from the IEM. The study highlighted that the relatively high prevalence resulted from the frequent consanguineous marriages (81.5\%) among affected families (Al Ali et al., 2006; Al fayez et al., 2018). The population of Emiratis is ethnically diverse that includes lineages from the Arabian Peninsula, 
Persia, Baluchistan, and East Africa. The culture is primarily tribal and encourages intertribal (consanguineous) marriages. As a result, "founder" mutations are prevalent, which markedly increase the frequency of autosomal recessive disorders (Ali et al., 2011).

The growing prevalence of IEM in the United Arab Emirates (UAE) will place a more significant financial strain on health systems and public health infrastructure across the region, translated as economic and psychosocial burdens on both the family and society. In a step to minimize the risk of the propagation of disease through the generation, a national newborn screening (NBS) test was introduced by the UAE government in 1995 so that early identification and treatment of these disorders can halt the number of physically and mentally challenged children in the community, thereby preventing morbidity and mortality due to these disorders (Al-Shamsi et al., 2016; Fukao and Nakamura, 2019).

At present, between 50 and 70 IEM have been recognized through gene analysis. A study conducted in UAE concluded that lack of knowledge of IEM among parents is a prominent factor that can lead to an increased number of neonates going undetected, resulting in serious health issues (Al Hosani et al., 2014). Therefore, the level of knowledge and attitude of the population regarding various aspects of the IEM is a necessary determinant for such programs' success. To the best of authors' review, there is a lack of published data regarding the awareness of IEM in the UAE region. Therefore, it is essential to conduct studies among the health science university students to assess the level of knowledge and attitude as they are an essential subgroup of the population since they have a relatively high education level.

\section{MATERIALS AND METHODS}

It was a cross-sectional questionnaire-based study carried out over 6 months among medical, dental, pharmacy, and nursing program students in one of the universities in the United Arab Emirates. The study was approved by the University Institutional Research and Ethics Committee (RAKMHSU-REC-096-2019UG-P). Subjects of both gender and pursuing either undergraduate or postgraduate programs in the medical or health science university were enrolled. Subjects who agreed to participate signed informed consent and then completed a questionnaire.

A self-administered knowledge and attitude questionnaire was developed after reviewing various literature and studies published (Al-Enezi and Mitra, 2017; Alfayez et al., 2018; Nijmeijer et al., 2019; Sandridge et al., 2010). The questionnaire was validated for its content by experts. The final questionnaire consists of three sections. The first section was related to the respondents' demographic characteristics (age, gender, nationality, college, academic year, and education level). The second section consists of questions to assess the knowledge regarding IEM such as hereditary nature, mode of transmission, the role of consanguineous marriages, skipping a generation in families, diagnosis, and management. The third sections consist of questions to assess the attitude of study respondents towards IEM within the family, premarital screening, blood relation marriages, and role of seminars and medical education about IEM in society and also about attitudes of respondents to take part in education programs in raising awareness of these disorders.

A convenient sampling technique was used to enroll the participants in this study. The questionnaires were distributed to all the study participants, and their responses were recorded.
There were nine questions related to knowledge, and each correct response was awarded one mark and an incorrect response with zero marks. Furthermore, respondents who scored $60 \%$ and above (knowledge score $\geq 5$ ) of the total score were categorized as having adequate knowledge, and others were considered having inadequate knowledge. Similarly, among nine questions related to attitude, each positive response was given a score of one and zero for each negative response. Respondents with a total score of $60 \%$ and above (attitude score $\geq 5$ ) were considered as having a positive attitude, and those with less than $60 \%$ (attitude score $<5$ ) were categorized to have a negative attitude. Collected data were entered into the excel sheet to ease the analysis. Statistical analysis was carried out by using Statistical Package for the Social Sciences version 24. Descriptive statistics were used to summarize the baseline characteristics of the study respondents. The $t$-test was used to examine the relationship between gender, nationality, education level, and age. The relationship between years of study and the overall scores was determined using analysis of variance (ANOVA). A Chi-square test was used to assess the relationship between the variables. A $p$-value of $<0.05$ was considered statistically significant.

\section{RESULTS}

A total of 414 students participated and completed the study, with the majority [257 (62.07\%)] of the respondents were females. The mean age of the study participants was $20.5 \pm 2.04$ years. Most [321 (77.53\%)] of the study participants were belonging to Arabs nationalities. More than $90 \%$ of the participants included in the study were pursuing their undergraduate programs. The predominant number of respondents was from dental $(36.47 \%)$, followed by medical $(24.87 \%)$, Pharmacy $(21.73 \%)$, and nursing (16.90\%) programs.

The study identified very low mean knowledge and attitude scores among the study participants. The mean knowledge and attitude scores by sociodemographic characteristics among study respondents were compared between the age groups (1520 and 21-25), gender (male and female), ethnicity (Arabs and non-Arabs), a program of study (medical, dental, pharmacy, and nursing), and education level (undergraduate and postgraduate). A statistically significant difference was observed among the mean knowledge and attitude scores of respondents in gender $(p<0.0005)$ and nationality $(p<0.0001)$ and among the various programs of study participants $(p<0.00001)$ (Table 1$)$.

Among 414 respondents, the majority [239 (57.7\%)] were aware of IEM. Lectures (30.74\%) followed by the Internet $(19.25 \%)$ and healthcare professionals $(18.72 \%)$ were the significant sources of information about IEM cited by our respondents. The study participant's response to a different source of information about IEM is shown graphically in Figure 1.

Regarding the knowledge of common IEM in the United Arab Emirates, the majority (53.14\%) of the study participants recognized only one correct answer, and $28.26 \%$ of the study participants spotted two correct answers from the multiple available answers. Of the total participants, $12.31 \%$ of students spotted "none of the above" as their choice. Similarly, questions related to identifying IEM symptoms were asked to the study participants by selecting multiple options as the correct answers. Only $28.5 \%$ recognized one correct answer, and $7.87 \%$ identified two correct answers from the provided multiple answers. 
Table1. Mean knowledge and attitude scores by sociodemographic characteristics among study respondents $(n=414)$.

\begin{tabular}{|c|c|c|c|c|c|}
\hline Characteristics & $n(\%)$ & Mean knowledge score & $\begin{array}{c}t \text {-statistic ( } p \\
\text { value) }\end{array}$ & Mean attitude score & $\begin{array}{l}t \text {-statistic } \\
(p \text { value })\end{array}$ \\
\hline \multicolumn{6}{|l|}{ Gender $^{a}$} \\
\hline Male & 157 & $2.85 \pm 1.75$ & \multirow[t]{2}{*}{$1.904(0.05)^{*}$} & $4.08 \pm 2.32$ & \multirow[t]{2}{*}{$2.128(0.03)^{*}$} \\
\hline Female & 257 & $3.19 \pm 1.77$ & & $4.61 \pm 2.54$ & \\
\hline \multicolumn{6}{|l|}{ Nationality ${ }^{\mathrm{a}}$} \\
\hline Arabs & 321 & $2.83 \pm 1.65$ & \multirow[t]{2}{*}{$5.096(<0.0001)^{*}$} & $4.23 \pm 2.47$ & \multirow[t]{2}{*}{$2.805(0.0053)^{*}$} \\
\hline Non - Arabs & 93 & $3.86 \pm 1.93$ & & $5.04 \pm 2.39$ & \\
\hline \multicolumn{6}{|l|}{ Education $^{\mathrm{a}}$} \\
\hline Undergraduate & 388 & $3.05 \pm 1.77$ & \multirow[t]{2}{*}{$0.586(0.5582)$} & $4.45 \pm 2.47$ & \multirow[t]{2}{*}{$-1.058(0.2907)$} \\
\hline Postgraduate & 26 & $3.26 \pm 1.75$ & & $3.92 \pm 2.52$ & \\
\hline \multicolumn{6}{|l|}{ Age in years ${ }^{\mathrm{a}}$} \\
\hline $16-20$ & 220 & $2.95 \pm 1.81$ & \multirow[t]{2}{*}{$1.321(0.1874)$} & $4.29 \pm 2.40$ & \multirow[t]{2}{*}{$1.068(0.2861)$} \\
\hline $21-25$ & 194 & $3.18 \pm 1.72$ & & $4.55 \pm 2.55$ & \\
\hline \multicolumn{6}{|l|}{ Colleges $^{\mathrm{b}}$} \\
\hline Medical & 103 & $4.23 \pm 1.80$ & \multirow{4}{*}{$\begin{array}{c}F=26.01 \\
(<0.00001)^{*}\end{array}$} & $5.33 \pm 2.07$ & \multirow{4}{*}{$\begin{array}{c}F=9.76 \\
(<0.00001)^{*}\end{array}$} \\
\hline Dental & 151 & $2.64 \pm 1.61$ & & $4.37 \pm 2.61$ & \\
\hline Pharmacy & 90 & $3.02 \pm 1.46$ & & $4.25 \pm 2.34$ & \\
\hline Nursing & 70 & $2.3 \pm 1.60$ & & $3.35 \pm 2.42$ & \\
\hline
\end{tabular}

${ }^{\mathrm{a}} t$-test.

${ }^{\mathrm{b}}$ ANOVA test.

$* p$ value $<0.05$.

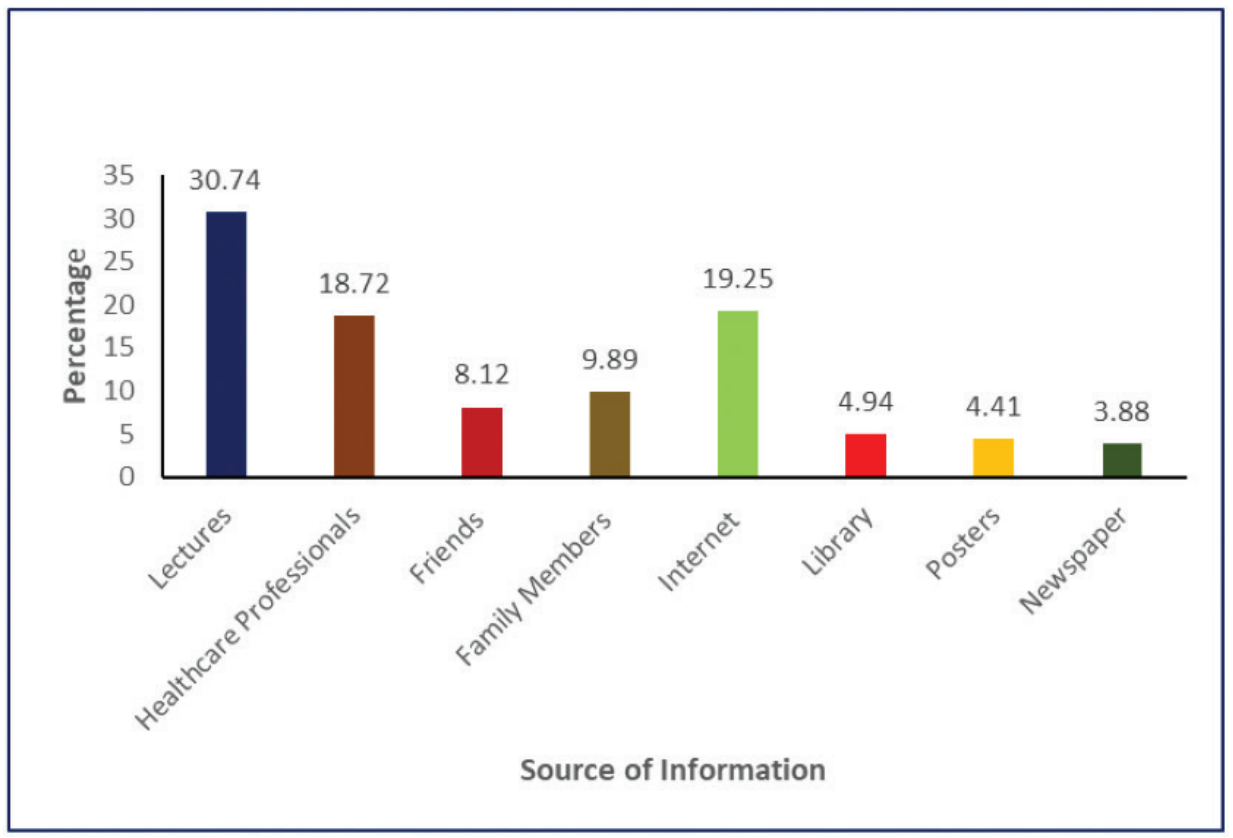

Figure 1. Study participants response to different source of information about inborn errors of metabolic disorders.

The study showed that more than half of the study participants had inadequate knowledge concerning identifying the cause of IEM (29.9\%), mode of transmission (24.8\%), and cure or management of the disorders (20.53\%). Only $30 \%$ of the total study participants were aware of the birth prevalence of IEM and the year in which the UAE government established the national neonatal screening program. Most of the study participants $(86.7 \%)$ revealed that they have never been tested for IEM and $85.5 \%$ of participants reported not having a hereditary disorder in the family. However, most of the participants (54.3\%) know that blood test is used to diagnose IEM. 
The majority of the respondents felt that IEM could be fatal if not treated appropriately [253 (61.1\%)] and agreed that early detection and management and appropriate methods may help to reduce the morbidity and mortality in the community [249 $(60.14 \%)]$, neonatal screening is mandatory [225 (54.3\%)], and blood relation marriages can increase the prevalence of these disorders $[235(56.7 \%)]$. Sixty percent of the study participants agreed on the importance of health education to the public about IEM to create awareness in society. A good percent [254 (61.3\%)] of the study participants believed that providing genetic counseling to improve public awareness of the transmission of inherited genetic disorders is necessary, while 238 (57.4\%) participants endorsed blood relation marriages will halt the IEM (Table 2).

The respondents' overall mean knowledge and attitude scores were $3.06 \pm 1.77$ (out of the total knowledge score of nine) and $4.41 \pm 2.47$ (out of the total attitude score of nine). The knowledge and attitude scores were compared by using the $t$-test. It revealed a statistically significant $(p<0.0001)$ difference between overall knowledge and attitude scores among the study respondents (Table 3 ).

The study identified inadequate knowledge [320 (77.2\%)] (total knowledge scores $\leq 4$ ) and adequate knowledge [94 (22.7\%)] (total knowledge scores $\geq 5$ ) among the study participants about these disorders. Furthermore, positive attitude (total attitude score $\geq 5$ ) was observed in more than $50 \%$ of the study participants $[218(52.6 \%)]$ with adequate and inadequate knowledge. We have also analyzed the association between levels of knowledge with a level of attitude among the respondents. It was observed that $144(66.1 \%)$ study participants with inadequate knowledge and $74(33.9 \%)$ with adequate knowledge had a positive attitude, and respondents with 176 (89.8\%) inadequate knowledge and $20(10.2 \%)$ with adequate knowledge were also having negative attitudes towards IEM, which is statistically significant $\left(X^{2}=33.1, p<0.00001\right)$ (Table 4).

\section{DISCUSSION}

IEM are rare metabolic diseases with heterogeneous clinical presentations and genetic etiologies affecting the pediatric and child population. Acquiring knowledge and adherence to pharmacotherapy are very important and require support from patients and families, healthcare providers, and nursery or school institutions. Simultaneously, the need of the hour is to focus on the target population, mainly the young adults like secondary schools and university students, because their knowledge and attitude towards health education will help prevent consanguineous marriages. It might reduce IEM in the community (Alotaibi and Irfan, 2017; Zeltner et al., 2019).

Our study found that the ages of respondents ranged between 16 and 25 years with young female predominance and were mostly undergraduates making them perfect for studying knowledge and attitude toward IEM. It helps individuals make informed decisions concerning their marriage to avoid the next generation affected by metabolic disorders.

In our study, the mean knowledge and attitude scores of female respondents were higher compared to males. The study

Table 3. Over all comparison of mean Knowledge and attitude scores among the study populations $(n=414)$.

\begin{tabular}{cccccc}
\hline Evaluation & Mean & Std. deviation & $\boldsymbol{n}$ & $\boldsymbol{t}$ & $\boldsymbol{p}$ \\
\hline Knowledge & 3.06 & 1.77 & 414 & & \\
Attitude & 4.42 & 2.47 & 414 & & \\
\hline
\end{tabular}

$* p$ value $<0.05$

Table 2. Responses about knowledge and attitudes about Inborn errors of metabolic disorders $(n=414)$.

\begin{tabular}{|c|c|c|}
\hline \multirow{2}{*}{ Knowledge } & \multicolumn{2}{|c|}{ Responses $n(\%)$} \\
\hline & Correct & Incorrect \\
\hline Ever heard about inborn errors of metabolic disorders & $239(57.72)$ & $175(42.27)$ \\
\hline Examples of inborn errors of metabolic disorders & $179(43.23)$ & $235(56.76)$ \\
\hline Cause of inborn errors of metabolic disorders & $124(29.95)$ & $290(70.04)$ \\
\hline Diagnosis of Inborn errors of metabolic disorders & $225(54.34)$ & $189(45.65)$ \\
\hline National neonatal screening program in UAE & $127(30.67)$ & $287(69.32)$ \\
\hline Prevalence of Inborn errors of metabolic disorders in UAE & $128(30.91)$ & $286(69.08)$ \\
\hline Cure for inborn errors of metabolic disorders & $85(20.53)$ & $329(79.46)$ \\
\hline Family members suffering from inborn errors of metabolic disorders & $60(14.49)$ & $354(85.50)$ \\
\hline Mode of transmission & $103(24.87)$ & $311(75.12)$ \\
\hline Attitude & Positive & Negative \\
\hline Inborn errors of metabolic disorders are more common in males than females & $97(23.42)$ & $317(76.57)$ \\
\hline Blood transfusion and bone marrow transplantation at early stage reduce morbidity \& mortality & $223(53.86)$ & $191(46.13)$ \\
\hline Inborn errors of metabolic disorders can be fatal & $253(61.11)$ & $161(38.88)$ \\
\hline Neonatal screening is mandatory & $225(54.34)$ & $189(45.65)$ \\
\hline Early detection and management reduce physically and mentally changed children & $249(60.14)$ & $165(39.85)$ \\
\hline Blood relation marriages lead to high prevalence & $235(56.76)$ & $179(43.23)$ \\
\hline Importance of medical education & $254(61.35)$ & $160(38.64)$ \\
\hline $\begin{array}{l}\text { Counselling aiming at improving public awareness about transmission and blood relation marriages will halt } \\
\text { these disorders }\end{array}$ & $238(57.48)$ & $176(42.51)$ \\
\hline
\end{tabular}


Table 4. Comparison of knowledge and attitude of respondents about inborn errors of metabolic disorders in UAE $(n=414)$.

\begin{tabular}{ccccc}
\hline \multirow{2}{*}{ Attitude } & \multicolumn{2}{c}{ Knowledge } & \multirow{2}{*}{ Total } & \multirow{2}{*}{$\boldsymbol{X}^{2}(\boldsymbol{p}$-value) } \\
\cline { 2 - 4 } & \multicolumn{2}{c}{ Adequate [Score 5-9] (\%) } & Inadequate [Score 1-4] (\%) & \\
\hline Negative attitude [Score 1-4] & $20(10.2)$ & $176(89.8)$ & 196 & $33.14(<0.00001)^{*}$ \\
Positive attitude [Score 5-9] & $74(33.9)$ & $144(66.1)$ & 218 & \\
\hline
\end{tabular}

$* p$ value $<0.05$

also found that the students from medical programs had higher mean knowledge and attitude scores than the students from other programs. It could be because medical students are better exposed to knowledge and as they implement it in practice, this enhances their IEM attitude. These findings were similar to the other studies, which showed that medical students had better knowledge as they interact more with patients suffering from these genetic disorders (Animasahun et al., 2009; Ugwu, 2016). Implementing a formal curriculum about genetic disorders across the programs will help bridge the knowledge gaps and make informed decisions and appropriate actions to prevent metabolic disorders.

One-third $(57.72 \%)$ of the respondents in our study have heard and were aware of IEM. The primary source of information about the IEM identified by the study respondents was from the lectures, followed by the Internet and healthcare professionals. This shows that schools/colleges and fast-growing information technology, including the Internet and media, have made the world a global village and can be an effective platform for educating people on genetic disorders. Health information delivered by the healthcare professional is most trusted by the public, even though other sources are available. This finding was similar to the other study, which cited that lecture, Internet, and health care professionals as the primary source of information (Manisha et al., 2016; Olakunle et al., 2013; Ugwu, 2016).

The study identified an overall low mean knowledge score despite a positive attitude, and the majority of the respondents were having scarcity about the knowledge of IEM and displayed some misconceptions. Inadequate knowledge was noticed in questions related to identifying the most common IEM in UAE, year of implementation of national neonatal screening program by the UAE government, birth prevalence of IEM among UAE population, recognizing the symptoms of the metabolic disorders, causes for the IEM, cure of the metabolic disorders, and family members suffering from metabolic disorders. However, most of the study respondents agreed that metabolic disorders could be life-threatening, and relation marriages can increase IEM risk.

The misconceptions include metabolic disorders inheritance pattern, diagnosis, and mode of transmission and indicate that questionnaire, at least in some aspects, was poorly understood by the study participants. These results emphasize the importance of more information and education about the students' metabolic disorders and put up a great responsibility on the health science colleges or institutions to introduce such a curriculum.

The majority of the respondents exhibited a positive attitude towards IEM. The study respondents had a positive attitude towards mandatory NBS tests for IEM, and early diagnosis and intervention of IEM may reduce the number of physically and mentally challenged children in the community. The study respondents also had a positive attitude towards counseling to improve public awareness of the transmission of metabolic disorders and endorsing blood relation marriages, which may halt the higher rates of IEM and early mortality in the community. The remaining proportions were found to have inadequate knowledge with a negative attitude. A study carried out in the Netherlands demonstrated an overall positive attitude among reproductive age participants in the general Dutch population towards preconception expanded carrier screening for autosomal recessive disorders, including IEM (Nijmeijer et al., 2019).

A retrospective study carried out in Iran examining the potential association between IEM and parental consanguineous marriages found a greater incidence of metabolic disorders in offspring of consanguineous parents than nonconsanguineous parents in a population with a relatively high rate of consanguinity. The study concluded that counseling for consanguineous marriages and newborn and prenatal screening for congenital metabolic disorders could reduce the rate of metabolic disorders and help treat affected infants (Keyfi et al., 2018).

Our study found that the overall mean knowledge and attitude scores were low among the study respondents. It is well known that, in patients suffering from chronic disease or disorders, effective health education improves knowledge and enhances adherence to treatment and successful self-management by influencing the patient's attitude and daily practice. These factors are necessary for optimal outcomes in patients with IEM. However, the low level of knowledge among the study respondents necessitates the need to include metabolic disorders-related topics in the college curriculum.

A pre- and poststudy carried out in Switzerland to develop and test specifically structured, comprehensible medical information on IEM for school-aged patients and their caregivers showed a higher percentage of knowledge gain in the posttest than in the pretest. Comprehensive knowledge about the disease will facilitate communication between the patient and the medical care team, thereby enhancing patient safety, outcome, attitude towards the care team, and quality of life (Zeltner et al., 2019). In another survey-based study in Hong Kong, assessing healthcare professions' knowledge and opinions on IEM identified significant knowledge gaps among the clinicians. They concluded a substantial need for better education among healthcare professionals about IEM (Mak et al., 2018).

Regarding the methods of spreading awareness, most of the study respondents agreed on the importance of seminars and medical education about IEM diseases/disorders in schools and societies. Providing understandable, balanced information and education, thereby creating awareness to the general public on the concepts of metabolic disorders, improves public knowledge about the disease and makes an informed decision about their marriages considering the risk of consanguinity marriages. Considering the increased incidence of genetic and metabolic disorders in the Middle East, implementing prevention programs that incorporate genetic counseling and mandatory NBS tests may enable early detection and treatment, providing better results and improved living conditions. 


\section{CONCLUSION}

The research showed a statistically significant difference between the knowledge and attitude scores about the IEM among the study participants, emphasizing the need for such health-related topics in their curriculum. Genetic health education targeting youths should be reinforced to improve their perceived comprehensive knowledge about IEM, especially on the consequences of blood relation marriages. It enables individuals to make informed decisions and actions and instill into the society the right attitude towards the consequent prevention and control of IEM.

\section{ACKNOWLEDGMENTS}

The authors want to express their gratitude to the President of the Medical and Health Science University and the Institutional Research Committee for permitting them to conduct the study. They are also very thankful to the Dean of the College of Pharmacy for providing the necessary support and encouragement to the study.

\section{AUTHOR CONTRIBUTIONS}

All authors made substantial contributions to conception and design, acquisition of data, or analysis and interpretation of data; took part in drafting the article or revising it critically for important intellectual content; agreed to submit to the current journal; gave final approval of the version to be published; and agree to be accountable for all aspects of the work. All the authors are eligible to be an author as per the international committee of medical journal editors (ICMJE) requirements/guidelines.

\section{FUNDING}

There is no funding to report.

\section{CONFLICTS OF INTEREST}

The authors report no financial or any other conflicts of interest in this work.

\section{PUBLISHER'S NOTE}

This journal remains neutral with regard to jurisdictional claims in published institutional affiliation.

\section{REFERENCES}

Al Ali MT, Al-Hashmi H, Mohammed N, Ahmed Z. New perspectives in inborn errors of metabolism: the Dubai experience. In Al Ali MT, Tadmouri GO (eds.). Genetic disorders in the Arab World-Bahrain. Center for Arab Genomic Studies, Dubai, United Arab Emirates, pp. 54-61, 2006.

Al Hosani H, Salah M, Osman HM, Farag HM, El-Assiouty L, Saade D, Hertecant J. Expanding the comprehensive national neonatal screening program in the United Arab Emirates from 1995 to 2011. East Mediterr Health J, 2014; 20(1):17-23.

Al-Enezi K, Mitra AK. Knowledge, attitude, and satisfaction of University Students Regarding premarital screening programs in Kuwait. Eur J Environ Public Health, 2017; 1(2):07.

Alfayez FM, Alamir MA, Alnahwi HA, Aleid DM, Alsheef HJ, Alzakari MJ. Maternal awareness and attitude about neonatal screening program in the Eastern Region of the Kingdom of Saudi Arabia. Egypt J Hosp Med, 2018; 70(2):265-72.

Ali BR, Hertecant JL, Al-Jasmi FA, Hamdan MA, Khuri SF, Akawi NA, Al-Gazali LI. New and known mutations associated with inborn errors of metabolism in a heterogeneous Middle Eastern population. Saudi Med J, 2011; 32(4):353-59.
Al-Jasmi FA, Al-Shamsi A, Hertecant JL, Al-Hamad SM, Souid AK. Inborn errors of metabolism in the United Arab Emirates: disorders detected by newborn screening (2011-2014). JIMD Rep, 2016; 28:127-35.

Alotaibi MS, Irfan UM. The knowledge, attitude and perception of Saudi adult population on consanguinity and genetic disorders. International Conference on Advances in Nursing, Pharmaceutical and Medical Sciences: ANPMS-2017, Kuala Lumpur, Malaysia, 2017. DIR1017310.

Al-Shamsi A, Hertecant JL, Al-Hamad S, Souid AK, Al-Jasmi F. Mutation spectrum and birth prevalence of inborn errors of metabolism among Emiratis: a study from Tawam Hospital Metabolic Center, United Arab Emirates. Sultan Qaboos Univ Med J, 2014; 14(1):e42-9; doi:10.12816/0003335

Al-Shamsi A, Hertecant JL, Souid AK, Al-Jasmi FA. Whole exome sequencing diagnosis of inborn errors of metabolism and other disorders in United Arab Emirates. Orphanet J Rare Dis 2016; 11(1):94.

Animasahun BA, Akitoye CO, Njokanma OF. Sickle cell: awareness among health professionals and medical students at the Lagos University Teaching Hospital, Lagos. Nig Q J Hosp Med, 2009; 19(4): $195-9$.

Fukao T, Nakamura K. Advances in inborn errors of metabolism. J Hum Genet. 2019; 64(2):65.

Keyfi F, Nasseri M, Nayerabadi S, Alaei A, Mokhtariye A, Abdolreza V. Frequency of inborn errors of metabolism in a Norteastern Iranian sample with high consanguinity rates. Hum Hered 2018; 83:71-8.

Mak CM, Law EC, Lee HH, Siu WK, Chow KM, Yeung SKCA et al. The first pilot study of expanded newborn screening for inborn errors of metabolism and survey of related knowledge and opinions of health care professionals in Hong Kong. Hong Kong Med J, 2018; 24(3):226-37.

Manisha S, Nehal S, Seema N, Radha K. Assessment of knowledge about hemophilia, a genetic bleeding disorder amongst paramedical and nursing students. Int J Multidiscip Res Dev, 2016; 3(3):168-71.

Nijmeijer SCM, Conijn T, Lakeman P, Henneman L, Wijburg FA, Haverman L. Attitudes of the general population towards preconception expanded carrier screening for autosomal recessive disorders including inborn errors of metabolism. Mol Genet Metab, 2019; 126(1):14-22.

Olakunle OS, Kenneth E, Olakekan AW, Adenike OB Knowledge and attitude of secondary school students in Jos, Nigeria on sickle cell disease. Pan Afr Med J, 2013; 15:127.

Sandridge AL, Takeddin J, Al-Kaabi E, Frances Y. Consanguinity in Qatar: knowledge, attitude and practice in a population born between 1946 and 1991. J Biosoc Sci, 2010; 42(1):59-82.

Shaafie IA, Raju ADV, Menon PK. Neonatal screening for inborn errors of metabolism - our experience at Cabri, Gulf Medical University. Gulf Med J, 2016; 5(S1):S35-42.

Ugwu N. Sickle cell disease: awareness, knowledge and attitude among undergraduate students of a Nigerian tertiary educational institution Asian Journal Med Sci, 2016; 7(5):87-92.

Zain AA. This health problem is most prevalent in UAE. Egypt J Hosp Med, 2017; 70(2):265-72. Available via https://www.khaleejtimes $\mathrm{com} /$ news/uae-health/this-health-problem-is-most-prevalent-in-uae (accessed on 10 October 2020).

Zeltner NA, Welsink-Karssies MM, Landolt MA, Bosshard Bullinger D, Keller F, Bosch AM, Groenendijk M, Grünert SC, Karall D, Rettenbacher B, Scholl-Bürgi S, Baumgartner MR, Huemer M. Reducing complexity: explaining inborn errors of metabolism and their treatment to children and adolescents. Orphanet J Rare Dis, 2019; 14:248.

How to cite this article:

Shareef J, Sridhar SB, Shariff A, Sabah MM, Hameed MY. Inborn errors of metabolism in the United Arab Emirates: Are our future healthcare providers knowing enough about it - A cross-sectional study. J Appl Pharm Sci, 2021; 11(10):093-098. 